\title{
LIFESTYLE PRACTICES AND PREVALENCE OF OBESITY IN A COMMUNITY WITHIN A UNIVERSITY CAMPUS
}

\author{
Moy FM and Atiya AS \\ Department of Social and Preventive Medicine, Faculty of Medicine, University of Malaya, 50603 Kuala Lumpur
}

\begin{abstract}
Malaysia has undergone rapid pace of industrialization and urbanization in recent decades and this has brought about imminent changes in the lifestyle of Malaysians. This is a cross-sectional study which attempts to examine the lifestyle practices and the prevalence of obesity of a group of security guards and their spouses of the University of Malaya, Kuala Lumpur. Data collection was conducted by both the methods of face-to-face interview and self-administered questionnaire. The respondents were surveyed on lifestyle practices such as smoking habits, exercise and eating pattern. Anthropometric measurement such as weight and height were also taken to establish the extend of obesity by using Body Mass Index (BMI). This study reveals that the community did have some unhealthy lifestyle practices such as smoking $(27.7 \% ; 95 \%$ CI $20.2 \%, 36.2 \%)$, low prevalence of adequate exercise $(13.8 \%$; $95 \%$ CI $8.4 \%, 21.0 \%)$; high prevalence of overweight and obesity $(64 \%$; $95 \%$ CI $55.1 \%$, 72.3\%); and high prevalence of co-morbidities such as diabetes mellitus and cardiovascular diseases. In conclusion, the community is considered to be a vulnerable and high-risk group for morbidity and mortality with the above predisposed risk factors. (JUMMEC 2003-2005; 8: 33-38)
\end{abstract}

KEYWORDS: Lifestyle practices, overweight and obesity

\section{Introduction}

Malaysia has undergone a rapid pace of industrialization and urbanization in recent decades and this has brought in changes in the lifestyles of Malaysians. These changes include reduction of physical activities, changes in dietary habits and food preferences which are more prone to high fat and high calorie diet (I). This has resulted in changes of nutritional status among the people in both the urban and rural dwellings where there is an increase of prevalence of overweight and obesity.

The Second National Health and Morbidity Survey (NHMS-II) in 1996 demonstrated an overall national prevalence (among population > 18 years of age) of overweight (BMI $>25 \mathrm{~kg} / \mathrm{m}^{2}$ ) of $16.6 \%$ and obesity (BMI $>30 \mathrm{~kg} / \mathrm{m}^{2}$ ) $4.4 \%$ (2). In urban areas, it was revealed that $29 \%$ males were overweight and $5 \%$ obese while $26 \%$ of females were overweight and $8 \%$ obese (3). As compared to another study conducted on urban executives in 1988, the prevalence of overweight and obesity was $28.7 \%$ and $2.7 \%$ respectively (4).

Overweight and obesity has resulted in the increase risks of premature death as well as increase morbidities such as diabetes mellitus, hypertension, hyper- lipidaemia, atherosclerosis, coronary heart disease, gout, gall bladder disease, respiratory diseases, arthritis and certain types of cancer (5-6). The objectives of this survey were to study the lifestyle practices and the prevalence of overweight/obesity of the community. This paper reports the findings of the community of Kampung Awal, which is located in the University of Malaya campus.

\section{Methods}

\section{Description of study area and study population}

Kampung Awal is a residential area built by the management of the University of Malaya for the security staff in the 70s. It is located in the main campus of the University of Malaya, close to the Faculty of Medicine. The purpose of having them staying in was for the security of the campus as well as convenience for the guards who have to work round the clock (shift work). There are 100 units of houses in this residential area with 102 staff and 96 spouses

Correspondence:

Moy Foong Ming

Department of Social and Preventive Medicine

Faculty of Medicine, University of Malaya

50603 Kuala Lumpur 
staying in. The study population included was mainly the heads of households and their spouses who were aged 18 to 58 years old. House to house visits were conducted and only those who were available during the home visits at the above mentioned period were surveyed. The total study population who responded was 136 respondents with 84 males and 52 females which made up a response rate of $68.7 \%$. The majority of males who did not respond were security guards with secondary education, while the female non-respondents were mainly working away from their houses and therefore unavailable during our home visits.

\section{Questionnaire}

Socio-demographic data, medical history and some lifestyle practices (including the habits of exercise, smoking, pattern of eating out, etc.) of the respondents were collected through a set of questionnaire which was pre-tested and modified before the study was implemented. Approval was obtained from the relevant authorities and informed consent was obtained from the respondents. All information was collected either by face-to-face interviews (58.8\%) or self-administered (4I.2\%) questionnaire. The filled questionnaires were checked with the respondents to clarify the unfilled questions or confused answers.

\section{Anthropometric measurement}

Anthropometric measurements including measurement of body weight and height of the respondents were taken. Respondents' weight was taken with bathroom weighing scale (spring balance scale). The weighing scale was calibrated regularly to ensure accuracy. Measurement was taken to the nearest 0.1 $\mathrm{kg}$. Two readings were taken for each respondent and the average weight was recorded.

Height of the respondent was taken by using a modified tape measure, Microtoise, which measured up to two metres. A direct reading of height to the nearest millimeter was obtained. Two readings were taken for each respondent and the average height was recorded.

\section{Body Mass Index (BMI)}

Body Mass Index (BMI) which is a weight $(\mathrm{kg})$ to height $^{2}\left(\mathrm{~m}^{2}\right)$ ratio was derived. Classification of $\mathrm{BMI}$ following the WHO (7) criteria is used.

\section{Data analysis}

All the variables listed in the questionnaire form was coded and entered into SPSS for Windows version 9.0. Appropriate statistical analyses were performed on the testable hypotheses using the same software. Students' t-test was conducted on continuous data while $\chi^{2}$ test was conducted on categorical data. Significant level was preset at $p=$ 0.05 . Confidence interval at $95 \%$ was also included wherever appropriate.

\section{Results}

\section{Demography data}

Out of the 136 respondents, 95.5\% $(n=130)$ were Malays and the remainder Indians. All respondents were included in the description of socio-demography data but for the analysis of lifestyle practices and anthropometric measurement, the Indians were excluded due to their small number. Another two female respondents who were pregnant were excluded too. Therefore, the total number of respondents analysed for anthropometric measurement was 128.

Table I shows some of the socio-demographic data of the study population. There were $60.3 \%$ of males and $39.7 \%$ females. The mean age of the population was 43.4 (sd = 7.5 years). Majority of them were married, working as security guards and had secondary education.

\section{Family history and prevalence of chronic diseases}

Twenty-three per cent $(n=32)$ of the study population had family history for diabetes mellitus and $47.1 \%$ $(n=64)$ for cardiovascular diseases which $36.0 \%$ $(n=49)$ for hypertension and II.0\% $(n=15)$ for heart disease (Figure I). Family members who had the above diseases could be their parents or siblings.

Table I. Socio-demographic data of the study population

\begin{tabular}{llrr}
\hline Characteristics & & \multicolumn{2}{c}{$\begin{array}{c}n \\
(\%)\end{array}$} \\
\hline Gender & Male & 82 & $(60.3)$ \\
& Female & 54 & $(39.7)$ \\
Marital status & Married & & \\
& Single & 133 & $(97.8)$ \\
& & 3 & $(2.2)$ \\
Occupation & Security guard & 84 & $(61.8)$ \\
& Housewife & $4 I$ & $(30.1)$ \\
& Unskilled worker & 1 I & $(8.1)$ \\
& & & \\
Education & No education & 2 & $(1.5)$ \\
& Primary & 39 & $(28.6)$ \\
& Secondary & 93 & $(68.4)$ \\
& Unknown & 2 & $(1.5)$ \\
\hline
\end{tabular}

Age $($ mean $\pm s d) \quad 43.4 \pm 7.5$ (years) 


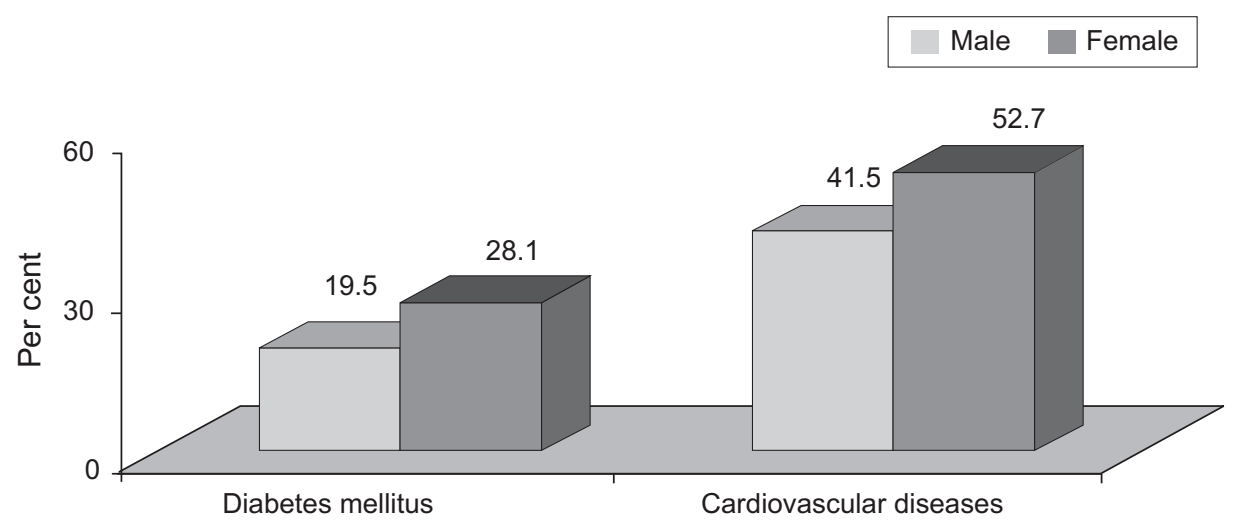

Chronic diseases

Figure I. Family history of chronic diseases of the study population by gender

Prevalence rate of such diseases was also obtained from the study by means of self-reporting by the respondents. The prevalence rate of known diabetes among the study population was $13.2 \%(95 \% \mathrm{Cl} 7.8 \%$, $20.1 \%$ ), whereas for cardiovascular diseases was $29.5 \%$ $(95 \% \mathrm{Cl} 21.6 \%, 37.8 \%)$ including hypertension and heart disease which were $22.1 \%(95 \% \mathrm{Cl} 15.5 \%, 30.4 \%)$ and $7.4 \%(95 \% \mathrm{Cl} 3.7 \%, 13.7 \%)$ respectively, and gout with a prevalence rate of $4.3 \%(95 \% \mathrm{Cl} 1.9 \%, 9.4 \%)$.

Figure 2 shows more information on the prevalence rate by gender. It could be observed that gout predominantly attacked the males in this study population. There was no statistical significant difference in the prevalence rates of diabetes mellitus $(p=0.845)$, hypertension $(p=0.585)$ and heart disease $(p=0.548)$ between the males and females.

\section{Physical exercise}

A person is considered to have ever exercise if he/she answered 'Yes' to the question whether he/she has ever carried out any type of exercise in the last two weeks. Exercise was considered to be adequate if he/she has performed one of the following 10 types of exercise: jogging, brisk walking, cycling, rope skipping, rowing, swimming, aerobics, team sports, racket sports and callisthenics sports (such as Taichi, Silat) for at least three times a week with each duration lasted 20 minutes or more (2).

Out of the total population $(n=130)$, only $5 \mid$ respondents $(39.2 \%, 95 \% \mathrm{Cl} 30.8 \%, 48.2 \%)$ ever exercised. There are significantly more males $(49.4 \%)$ taking part in exercise compared to females $(24.5 \%)(p=0.004)$.

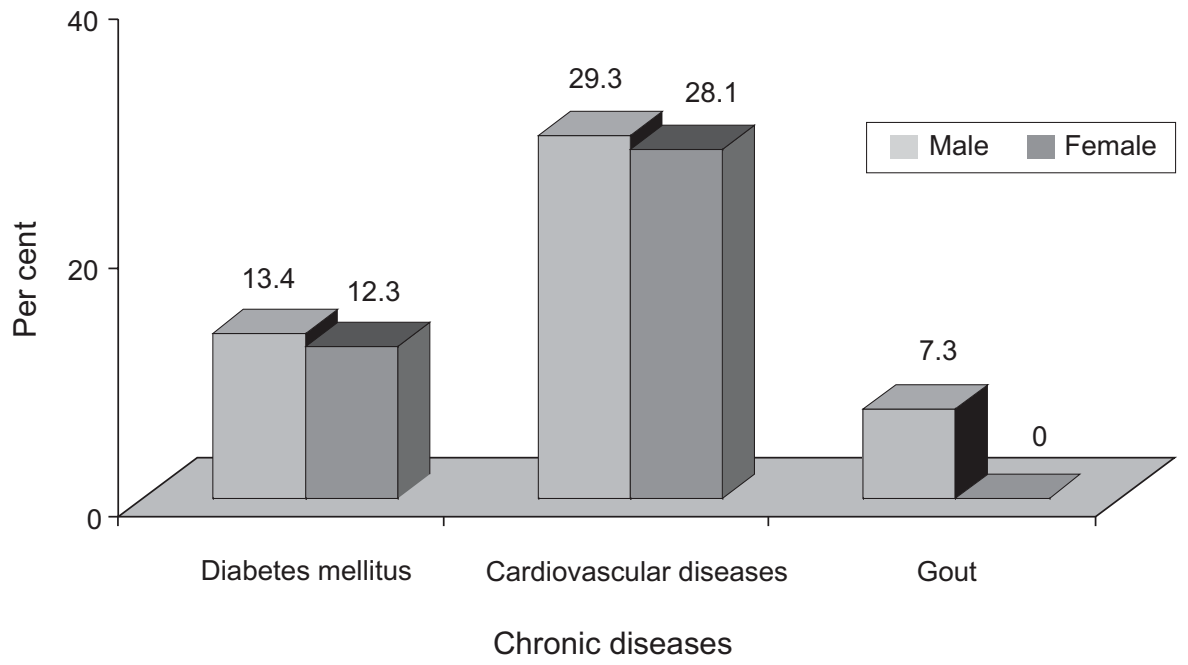

Figure 2. Prevalence rates of chronic diseases among the study population by gender 
When the respondents were asked why they did not exercise, the most frequently cited reasons were busy (84.8\%), not feeling well $(7.6 \%)$ and others (dislike, unnecessary, etc.).

The three most common types of exercise carried out by the respondents ( $n=51$ ) were jogging (34.6\%), walking (19.2\%), team sports (13.5\%) and others (30.7\%), which included racket games, weight lifting, cycling, exercise on machines, body movement and rope skipping. Team sports such as hockey, football were mainly participated by males. The frequencies of exercise among those who ever exercised were daily (I7.3\%), three times a week (34.6\%), once a week $(26.9 \%)$ and less than once a week (17.3\%). The duration of each session was less than 20 minutes (29.4\%, $n=15), 20$ to 60 minutes $(47.1 \%, n=24)$ and more than an hour $(19.6 \%, n=10)$ with $3.9 \%(n=2)$ unknown.

When the prevalence rate of adequate exercise was calculated, it was found that only $13.8 \%(n=18)(95 \% \mathrm{Cl}$ $8.4 \%, 21.0 \%$ ) of the respondents exercised adequately. This gives a percentage of only $35.3 \%$ of those who ever exercised did it adequately.

\section{Smoking habits among the study population}

The prevalence rate of smoking among the study population was $27.7 \%(n=36)(95 \% \mathrm{Cl} 20.2 \%, 36.2 \%)$ with all smokers being males. The prevalence rate of smoking among the males $(n=77)$ was $46.8 \%$. The mean year of smoking was 18.4 (sd $=6.0$ years). Most of the smokers $(86.1 \%)$ had smoked from 10 to 29 years.

All of the smokers were smoking cigarettes. The mean number of cigarettes smoked a day was 15.3 (sd = 8.6). Among those who did not smoke currently $(n=94)$, I 3 (I3.8\%) of them had smoked before and all of them were males. The mean duration of smoking before cessation for these ex-smokers was II.9 (sd = 9.1 years).

\section{Eating pattern}

Eating pattern of the study population was surveyed. The respondents were asked if they have the habits of eating out. It was found that 59 respondents $(45.4 \%$, $95 \% \mathrm{Cl} 36.6 \%, 54.3 \%$ ) did have the habits of eating out with 47 males $(61.0 \%)$ compared to 12 females (22.6\%). The most frequently visited eating places were hawker stalls (44.3\%) and cafeteria/canteen (39.3\%) while fast food restaurants $(9.8 \%)$ such as KFC, McDonalds were the favourite among the younger couples with younger children. Other places of eating out were restaurants $(3.3 \%)$ and the remainder unknown.

\section{Consumption of vegetables and fruits}

This study shows that 118 of the respondents $(90.8 \%$, $95 \% \mathrm{Cl} 84.4 \%, 95.1 \%$ ) took vegetables daily. Those who did not consume vegetables regularly gave reasons such as dislike, unnecessary, etc.

The consumption of fruits among the study population was lower where only 96 of the respondents $(73.8 \%$, $95 \% \mathrm{Cl} 65.4 \%, 81.2 \%)$ consumed fruits daily. There were significantly more males $(84.4 \%)$ who consumed fruits daily compared to females $(58.5 \%)$ ( $p<0.0$ I). Types of fruits consumed were mainly local fruits (37.1\%) or imported fruits $(9.3 \%)$ or both $(53.6 \%)$. Reasons for not consuming fruits daily were mainly unavailability (6I.1\%), dislike (16.7\%), expensive (5.5\%) and others unknown. More female respondents cited the reason of unavailability compared to males.

\section{Anthropometric measurement}

The mean weight and height of the respondents $(n=\mid 28)$ were $68.9(\mathrm{sd}=11.9 \mathrm{~kg})$ and $16 \mathrm{I} . \mathrm{I}(\mathrm{sd}=8.5$ $\mathrm{cm}$ ) respectively. For the mean weight and height of the males and females, the results were as shown in Table 2. The males were statistical significantly heavier and taller than the females $(p<0.0 \mathrm{I})$.

Table 2. Anthropometric indicators of the study population by gender

\begin{tabular}{|c|c|c|c|}
\hline Anthropometric Indicators & $\begin{array}{l}\text { Total Population } \\
\qquad \begin{array}{c}(n=128) \\
\bar{x} \pm s d\end{array}\end{array}$ & $\begin{array}{l}\text { Males } \\
(n=77) \\
\bar{x} \pm \text { sd }\end{array}$ & $\begin{array}{l}\text { Females } \\
(n=5 I) \\
\bar{x} \pm s d\end{array}$ \\
\hline Weight (kg) & $68.9 \pm 11.9$ & $72.6 \pm 10.5$ & $63.2 \pm 11.8$ \\
\hline Height (kg) & $|6| . \mid \pm 8.5$ & $166.5 \pm 5.2^{*}$ & $152.9 \pm 5.4$ \\
\hline $\mathrm{BMI}\left(\mathrm{kg} / \mathrm{m}^{2}\right)$ & $26.5 \pm 4.0$ & $26.2 \pm 3.4^{*}$ & $27.0 \pm 4.8$ \\
\hline
\end{tabular}

\footnotetext{
$* p<0.05$ within gender
} 


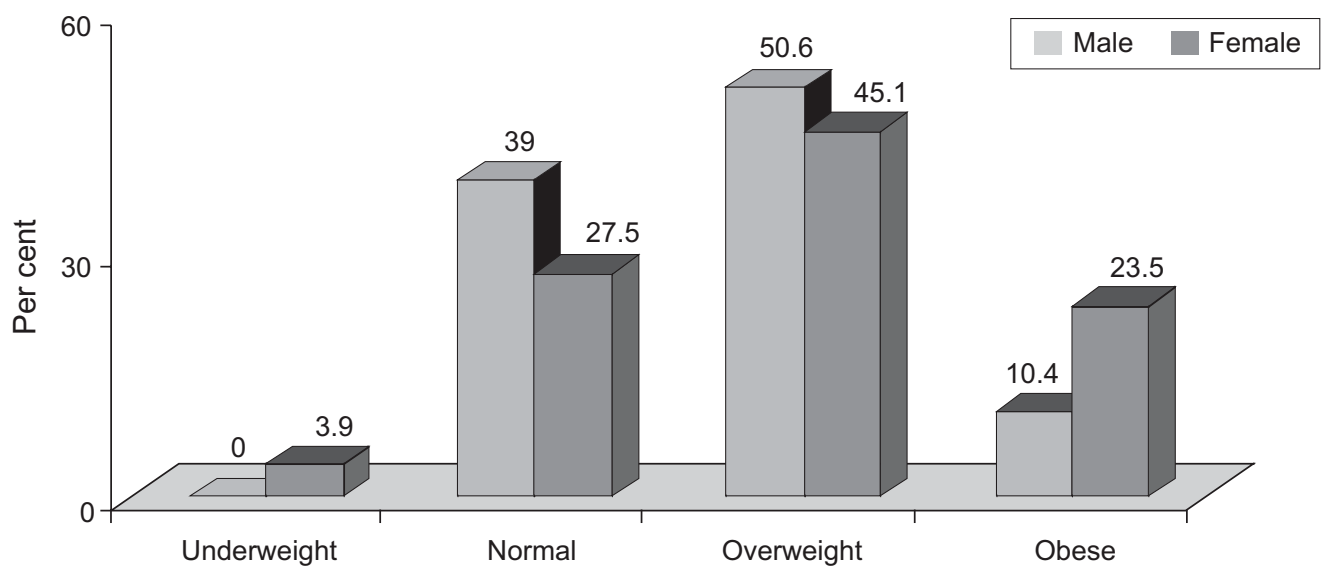

BMI Classification

Figure 3. Classification of subjects into BMI categories by gender

The mean BMI of the population was 26.5 (sd $=4.0$ $\mathrm{kg} / \mathrm{m}^{2}$ ) with males' and females' BMI being 26.2 $\left(\mathrm{sd}=3.4 \mathrm{~kg} / \mathrm{m}^{2}\right)$ and $27.0\left(\mathrm{sd}=4.8 \mathrm{~kg} / \mathrm{m}^{2}\right)$ respectively (Table 2). The difference of BMl among gender was not statistically significant $(p=0.246)$. Figure 3 shows the $\mathrm{BMI}$ of the respondents in categories of underweight, normal, overweight and obese following WHO (7) criteria by gender.

From Figure 3, it could be observed that only $34.4 \%$ of the study population was of normal weight with more males (39.0\%) than females (27.5\%). While 64\% $(95 \% \mathrm{Cl} 55.1 \%, 72.3 \%)$ of the study population were overweight $\left(\mathrm{BMI}>25.0 \mathrm{~kg} / \mathrm{m}^{2}\right)$. However, there were I5.6 per cent $(95 \% \mathrm{Cl} 9.8 \%, 23.1 \%)$ of the population in the obese category $\left(\mathrm{BMI}>30 \mathrm{~kg} / \mathrm{m}^{2}\right)$. For the overweight group, the proportion of males and females were about the same $(50.6 \%$ and $45.1 \%$ respectively). But for the obese group, there were $10.4 \%$ males compared to $23.5 \%$ females. There was only I.6\% of the study population underweight who were primarily females.

\section{Discussion and Conclusions}

The results show that majority of this study population is overweight with increased risk of co-morbidity and having higher prevalence of chronic diseases such as diabetes mellitus and cardiovascular diseases as compared to the national figures (2).

When the respondents were classified into categories of underweight, normal, overweight and obese following the WHO criteria (7), it was found that over $60 \%$ of the respondents were either overweight or obese.
Compared to the NHMS-II (2) data for both the prevalence of overweight/obesity for all races or only Malay population only, the prevalence of this study population is very much higher. This could be attributed to their older age compared to the NHMS-II since it is noted that overweight and obesity tend to increase with age (8-9).

Although the difference of BMI among gender was not statistically significant, but the proportion of overweight males $(50.6 \%)$ were higher compared to females $(45.1 \%)$ while the proportion of obese females $(23.5 \%)$ were higher than males (10.4\%). These findings are comparable to the study of (3) in urban areas and the Singapore National Health Survey (9) conducted in 1998 where both studies had more overweight males and more obese females. Obesity in females was found to be rising after marriage and with parity (8).

Although the prevalence rates of ever exercise and adequate exercise of this study population were higher than the national figures (2), but it still is considered low since there are about $60 \%$ of the respondents who did not exercise at all. This sedentary lifestyle will lead to increase in body weight as well as higher risk of chronic non-communicable diseases. Therefore, it is important to motivate the respondents to adopt healthy lifestyle in particularly in exercise.

Among the ethnic groups in the NHMS-II (2), Malays had higher prevalence of smoking (27.9\%) compared to Chinese (19.2\%) and Indians (16.2\%). This study population which predominantly was from the Malay ethnicity had a current smoking prevalence (27.7\%) which is close to the national figure (2). 
Cigarette smoking is a major risk factor for hypertension, heart disease, stroke, cancer and chronic obstructive lung disease (10) and has been identified as the single most avoidable cause of death in countries such as United Kingdom (II) and the United States (10). The WHO estimates that annual tobacco attributable death will reach 8.4 million in 2020 and 10 million in 2030 (10). In view of the adverse consequences of cigarette smoking, health intervention needs to be initiated for this community to quit smoking.

Dietary habits such as consumption of fibre (contributed by vegetables and fruits) as well as pattern of eating out are also surveyed in this community. It could be observed that the habit of consuming vegetables regularly was being practiced by most of the respondents. However, the adequacy of fibre intake in this community is not available due to the inaccessibility of quantitative data. Respondents who used to eat out need to be advised on healthier food choices which are lower in calorie, fat, sugar and salt. Those who frequented the fast food outlets also need to be advised to reduce or stop this eating habit since fast food has high calorie, high fat and high sodium contents.

No significant association was found among the status of obesity (BMI) with the above mentioned variables such as gender, education, exercise, medical history such as diabetes mellitus and heart diseases, cigarette smoking, pattern of eating out, consumption pattern of vegetable and fruits. This could be due to the small sample size of the study population. More thorough investigation needs to be carried out to verify these findings.

The non-respondents who might be the less healthy and less motivated to practise healthy lifestyle could also serve as a confounding factor in the analysis.

In conclusion, this study finds that the community of Kampung Awal practises unhealthy lifestyle such as smoking, low prevalence of exercise; had high prevalence of diabetes mellitus and cardiovascular diseases and high prevalence of overweight/obesity. On the other hand, the habits of consuming vegetables and fruits are still being practised. Nevertheless, the unhealthy lifestyle practices and the obesity status are indicative of their vulnerability for chronic diseases such as diabetes mellitus, hypertension and cardiovascular diseases. Health promotion and health education targeted to increase awareness on healthy lifestyles should be specially planned for them.

\section{Acknowledgements}

The authors express their most sincere gratitude to the Department of Social and Preventive of Medicine, the Registrar of the Human Resource and the Director of the Security Office of University of Malaya; the Penghulu and all the residents of Kampung Awal in giving their support in the conduct of the survey. Our gratitude also goes to Encik Mohd Shukri for his assistance in the field and all those who helped in the survey.

\section{References}

I. Tee ES. Obesity in Asia: prevalence and issues in assessment methodologies. Asia Pac J Clin Nutr 2002; II(3):S694-S70I.

2. Report of the Second National Health and Morbidity Survey (NHMS-II). Ministry of Health Kuala Lumpur, 1997.

3. Ismail MN, Zawiah H, Chee SS, et al. Prevalence and obesity and chronic energy deficiency (CED) in adult Malaysians. Malays J Nutr 1995; I:I-9.

4. Teo PH, Chong YH, Zaini AR. Coronary risk factors among Malaysian male executives in two urban areas. Med J Malaysia 1988; 43:125-133.

5. Pi-Sunyer FX. Medical hazards of obesity. Ann Intern Med 1993; I1 19:655-660.

6. American Obesity Association. 2000. Justification for obesity as a leading health indicator. Internet communication at http://www.obesity.org/AOA_HP2010.html (accessed on 10.6.00).

7. WHO. Obesity: preventing and managing the global epidemic. Report of a WHO consultation on Obesity. Geneva:World Health Organisation. 1997.

8. McNulty SJ, Williams G. Obesity: an overview. 2000. Internet communication at http://www.rcpe.ac.uk/ public/volume29_3a.html (accessed on 15.12.00).

9. Singapore National Health Survey. 1998. Internet communication at http://www.gov.sg/moh/health_survey/ NHSODF.htm (accessed on I4th June 2000).

10. WHO 200I. Tobacco Free Initiative. Health Impact. Internet communication at http://tobacco.who.int/ en/health/index.html (accessed on the 22.2.0I).

II. Erens B, Primatesta P. (eds) Risk factors for cardiac diseases: cigarette smoking. In: Health Survey for England: Cardiovascular Disease 98, Volume 2. 1999; London: The Stationary Office. 